\title{
Mission design, preflight and flight performance and observations for Pad Abort Test
}

\author{
Jayanta Dhaoya*, N. Remesh, C. Ravikumar, P. Bhanumathy, A. K. Anilkumar, \\ Abhay Kumar and V. Ashok
}

Vikram Sarabhai Space Centre, Thiruvananthapuram 695 022, India

\begin{abstract}
Abort system is initiated to take the Crew Module (CM) away from the launch vehicle in case of an emergency at lift-off or at any point of time after launch for a mission with crew onboard. Crew Escape System (CES)-based abort is carried out from launch pad and during the atmospheric phase of ascent flight. The design and operation of CES play a crucial role in providing abort capability for escape from launch vehicle and return of the crew back to Earth during critical phase of ascent flight. CES motors are used to pull CM away from the launch vehicle during this mode of abort. Mission simulation and analysis is necessary for the design of CES-based abort mission and for its configuration. This article discusses the mission design, challenges faced during the design and strategies formulated towards the successful execution of Pad Abort Test.
\end{abstract}

Keywords: Abort system, flight performance, launch vehicle, mission design.

\section{Introduction}

THE Crew Escape System (CES) provided in human-rated launch vehicle is designed to be functional from lift-off, when the vehicle is on the launch pad, to just after ignition of second stage of the launch vehicle. Launch abort system provides reliable capability for abort within the atmosphere $^{1-3}$. During launch pad abort phase, abort motors and pitch motors with suitable selection of design parameters such as ignition time, Crew Module (CM) separation time, and total impulse and thrust level aid CES to move out of the flight path of the launch vehicle ${ }^{4}$. After separation of CM from CES, the parachute kept in the area of CM will be deployed for safe recovery of CM. During the parachute deployment phase, the CM has to be oriented to have its heat shield base facing the flow such that velocity vector is aligned opposite to parachute drag. Therefore, it is necessary to provide a reorientation system (active) before separation. In the absence of an active reorientation system, the $\mathrm{CM}$ itself (passive - due to its

*For correspondence. (e-mail: jayanta-hsfc@isro.gov.in) aerodynamic stability) must be capable of aligning to heat shield forward attitude, i.e. CM will reorient by itself due to aerodynamics or the velocity vector rotates to favourable orientation (flight path angle change) due to gravity. Figure 1 shows the pad abort configuration of the vehicle. It has three sets of motors: Low-altitude Escape Motor (LEM) with four reverse nozzles, four High-altitude Escape Motors (HEM) and a Pitch Motor (PM). LEM and HEM provide sufficient acceleration levels to move out of the launch pad and PM provides lateral range with pitch manoeuvre.

The major design requirements for the launch pad abort mission are (i) to finalize the thrust and impulse of abort motors such that the CES can take CM safely beyond the specified range limits within the specified duration,

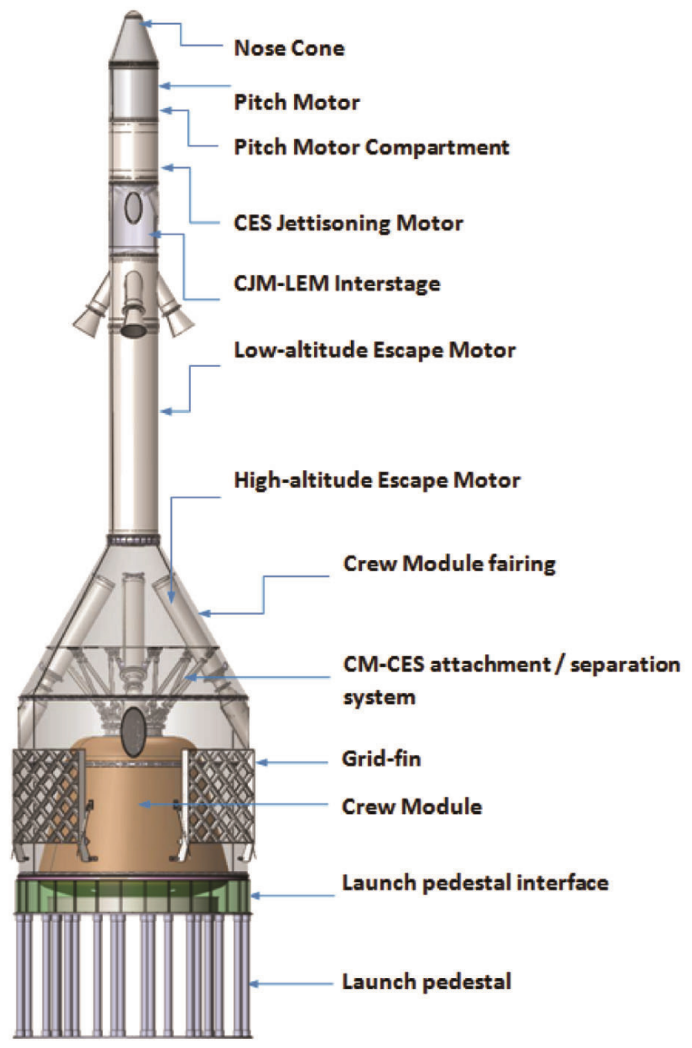

Figure 1. Crew Escape System (CES) vehicle configuration. 


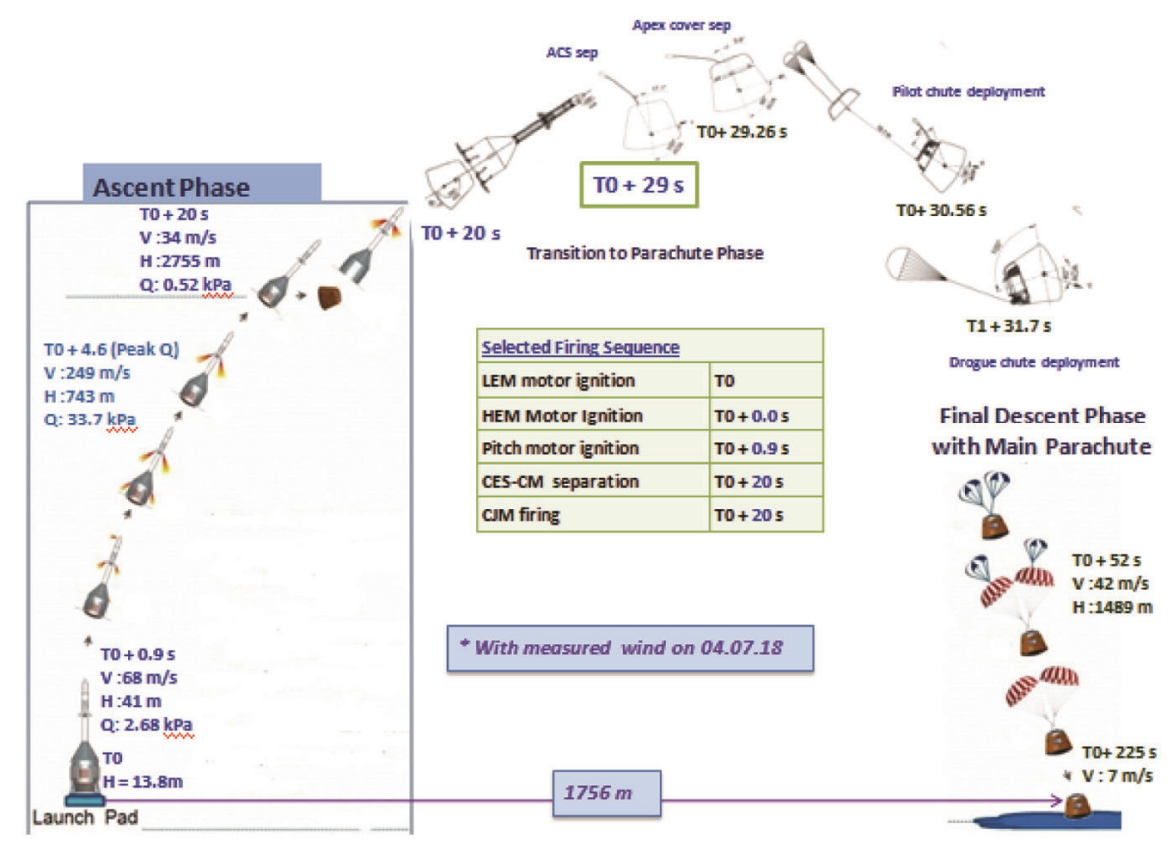

Figure 2. Pad Abort Test - mission profile.
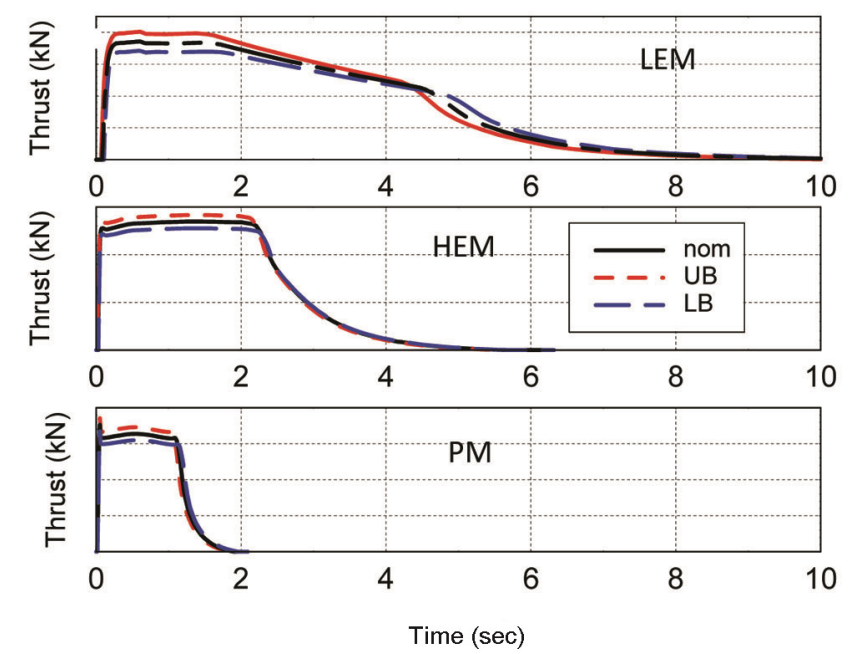

Figure 3. Sea-level thrust profiles of abort motors.

(ii) to finalize the sequence and timing of operations of the motor ignition, $\mathrm{CM}$ separation time and parachute deployment initiation time during the $\mathrm{CM}$ flight phase. Figure 2 shows a typical pad abort mission sequence of events. The assessment of influence of wind on stability aspects of the vehicle and identification of appropriate timing of launch to acquire wind assistance for impacting at safe range from the launch pad are also essential. This requirement is crucial for pad abort mission since it is planned for an uncontrolled abort. CM oscillations and its attitude need to be within the specified limits during initiation and deployment of the parachute system. Therefore, accurate modelling of the aerodynamic forces and moments along with vehicle dynamics considering wind are major design requirements.

For the first design requirement, the thrust levels of motors are appropriately sized and the motors are realized accordingly to meet the specified peak altitude, impact range and specified distance travel within the specified duration. The specified thrust level of abort motors is obtained after two static tests of the motors (Figure 3). The second and third requirements of the pad abort mission are considered in this article. Details of Pad Abort Test (PAT) flight performance and its comparison with preflight are also provided.

\section{Mission objectives and specifications}

For pad abort initiation from the launch pad, viz. PAT, Crew Escape Motors pull CM to an altitude of $2.5 \mathrm{~km}$ approximately for the normal operation of deceleration systems and take CM to a safe distance from the launch pad to have CM impact on sea.

Following are the mission specifications.

- Peak altitude $>2.5 \mathrm{~km}$.

- Impact range $>400 \mathrm{~m}$ from the launch pad.

- Dynamic pressure at CES/CM separation $\leq 3 \mathrm{kPa}$.

At the time of CM separation from CES, apex of CM that contains the parachute systems is aligned with the velocity vector due to mounting in the ascent configuration. This attitude is unfavourable for parachute deployment process as $\mathrm{CM}$ angle of attack (AOA) is about $\pm 180^{\circ}$. In the present $\mathrm{PAT}, \mathrm{CM}$ reorientation after its separation 
from Crew Escape system is in passive sense, implying that $\mathrm{CM}$ will reorient by itself due to aerodynamic moment and/or the velocity vector rotates to favourable orientation for parachute deployment process (flight path angle change) due to gravity. Parachute initiation sequence starts with the deployment of Apex Cover Separation (ACS) parachute followed by ACS. Subsequently pilot chute will be deployed with the help of mortar firing to pull the drogue parachute that would pull the main parachute at predefined time.

\section{CES mission strategies and challenges in trajectory design}

The CM impact range is achieved by firing PM at suitable time based on the requirement. The early PM firing will provide more impact range while dynamic pressure at CES separation will be more and vice versa. The other constraint on $\mathrm{CM}$ regarding AOA during the pilot mortar firing to drogue parachute initiation depends on initial condition at $\mathrm{CES} / \mathrm{CM}$ separation, i.e. dynamic pressure and body rate of $\mathrm{CM}$. The higher the dynamic pressure, the body rate results in larger attitude oscillations violating the AOA constraint during the parachute deployment phase. To meet the constraint on AOA, the dynamic pressure and body rate at CES/CM separation must be small enough so that reorientation of CM will occur due to gravity force, i.e. flight path angle change and the effect of aerodynamics on CM is minimal. In this scenario, CES pitching needs to be delayed by firing PM at a later instance with respect to the lift-off time, so that dynamic pressure at separation will be minimal at the cost of sacrificing the impact range (in the absence of wind). If the PM is fired on the launch pad, the down range achieved will be more (in the absence of wind). In this case the dynamic pressure and body rate at CM separation will be higher. Therefore, the requirements of $\mathrm{CM}$ impact range and AOA of separated CM are contradictory in nature.

Figure 4 shows the pitching moment coefficient versus AOA for $\mathrm{CM}$ at subsonic Mach number. This figure shows that there are three AOA trim points and they are $-110^{\circ}, 0^{\circ}$ and $110^{\circ}$.

For safe deployment of the parachute, it is necessary to have the trim AOA points within $\pm 40^{\circ}$ (oscillations about $0^{\circ}$ AOA with heat shield forward attitude). As discussed earlier, at the time of CM separation from CES, CM AOA is about $\pm 180^{\circ}$. At $180^{\circ} \mathrm{AOA}, \mathrm{CM}$ is statically and dynamically unstable. With higher dynamic pressure (more than $1 \mathrm{kpa}$ ) at $\mathrm{CM}$ separation, the effect of aerodynamic instability is higher, resulting in faster rotation of $\mathrm{CM}$, and it is difficult to achieve favourable AOAs during the parachute deployment process. Also, the body rate at parachute deployment will be higher than the limits for safe parachute deployment. If the dynamic pressure at separation is very low (less than $300 \mathrm{~Pa}$ ), there is a possibility of $\mathrm{CM}$ to rotate from $180^{\circ} \mathrm{AOA}$ and trim around $110^{\circ}$ during the parachute deployment phase, which is not a preferred orientation for proper parachute deployment. Hence it is essential that the dynamic pressure at separation be within a narrow range, viz. 300-1000 Pa to ensure AOA oscillations at parachute deployment within $\pm 40^{\circ}$. To achieve this narrow range of dynamic pressure at separation, the ignition time of three motors of CES along with CM separation time must be optimally selected.

The following strategies are formulated for PAT:

- Optimizing the motor ignition sequence to maximize the impact range satisfying the constraint on $\mathrm{CM}$ AOA during parachute deployment process without considering wind.

- The shortage, if any, in specified impact range can be achieved by selecting a suitable wind which will assist in improving the impact range by means of parachute drift during the descent phase.

To arrive at optimum mission sequence (to maximize the impact range), a grid search is used with six degrees of freedom simulation for Crew Escape system and the CM. After CM separation, parachutes are deployed and the trajectory simulated to find the impact time, location and velocity. The design parameters for the grid search are:

- Ignition time of LEM, HEM and PM.

- $\mathrm{CM} / \mathrm{CES}$ separation time.

The following case definitions are used for the grid search:

- Nominal.

- LB (minimum range) - thrust profile $(-3 \sigma)$ and all others $1 \sigma$ dispersion for minimum range.

- UB (maximum range) - thrust profile $(3 \sigma)$ and all other $1 \sigma$ dispersion for maximum range.

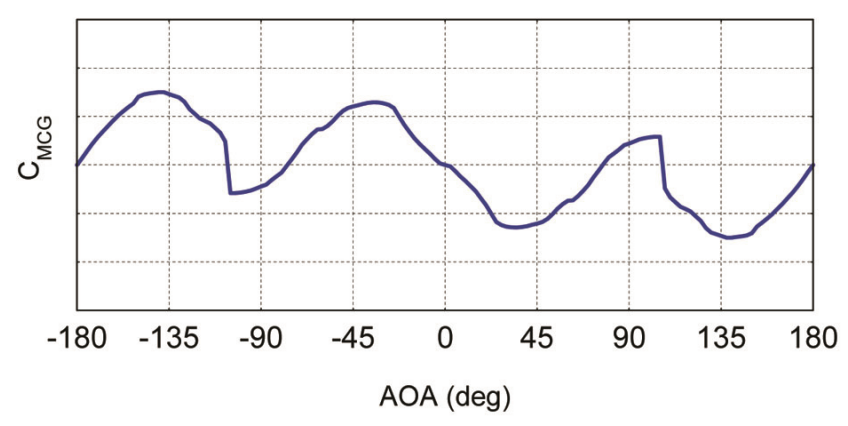

Figure 4. Crew Module (CM) pitching moment coefficients. 
Table 1. Trajectory parameters for finalized sequence (no wind case)

\begin{tabular}{|c|c|c|c|c|c|c|c|}
\hline \multirow{2}{*}{$\begin{array}{l}T 0=0 \mathrm{sec} \\
\Delta t_{1}(\mathrm{sec})\end{array}$} & \multirow{2}{*}{$\begin{array}{c}\text { PM, } \\
\Delta t_{2}(\mathrm{sec})\end{array}$} & \multirow{2}{*}{$\begin{array}{c}\text { Sep, } \\
\Delta t_{3}(\mathrm{sec})\end{array}$} & \multirow{2}{*}{$\begin{array}{l}\text { Alt. @ } \\
\text { sep (m) }\end{array}$} & \multirow{2}{*}{$\begin{array}{c}\text { Q.@ } \\
\text { Sep (Pa) }\end{array}$} & \multicolumn{2}{|c|}{ (a) parachute deploy (29 sec) } & \multirow{2}{*}{$\begin{array}{c}\text { Down } \\
\text { range }(\mathrm{m})\end{array}$} \\
\hline & & & & & Alt (m) & $\mathrm{Q}(\mathrm{Pa})$ & \\
\hline Min. range & & & 2718 & 569 & 2634 & 1142 & 324 \\
\hline Nom & 0.9 & 20 & 2748 & 551 & 2653 & 1216 & 445 \\
\hline Max. angle of attack & & & 2857 & 719 & 2795 & 1123 & 616 \\
\hline
\end{tabular}

Based on all the above requirements and constraints the motor ignition sequences are finalized through simulation without considering wind in the design phase. It may be noted that winds are considered for performance simulation studies. The finalized sequences are as follows:

LEM and HEM ignition at: T0 sec.

PM ignition at: $\mathrm{T} 0+0.9 \mathrm{sec}$.

CES/CM separation: $\mathrm{T} 0+20 \mathrm{sec}$.

Table 1 shows typical trajectory parameters for the finalized sequences.

The table shows that impact range is not met for minimum range case with finalized sequences. So it is essential to have a favourable wind to meet the specified impact range. Detailed simulation studies considering winds are conducted, and it is concluded that wind from land to sea (positive zonal component) is required to meet the specified impact range limit of $400 \mathrm{~m}$ from launch point. Also, it concluded that winds during June/July over SHAR range will help attain the specified impact range. However, if the constraint of $40^{\circ}$ on total AOA during parachute deployment is relaxed, then constraint on wind direction could also be relaxed.

\section{Effect of wind on mission performance and launch day wind measurements}

As discussed in the previous section, winds have significant effect on impact range during $\mathrm{CM}$ phase with the parachute. To evaluate the effect of wind on impact range, a large number of June wind profiles measured during 5 and $10 \mathrm{a} . \mathrm{m}$. between 16 and 30 June from 2014 to 2017 at $20 \mathrm{~m}$ intervals are considered (Figures 5 and 6).

Simulations are carried out for nominal and off nominal cases yielding minimum and maximum range cases for all the measured winds considered for simulation. Figures 7 and 8 show the simulation results with the above mentioned wind profiles. Figure 7 shows altitude versus down range plot for all the simulation cases. It can be seen from the figure that in all cases the minimum impact range requirement is satisfied. AOA requirement $\left(<40^{\circ}\right)$ during parachute deployment is also met for all the simulation cases (Figure 8).

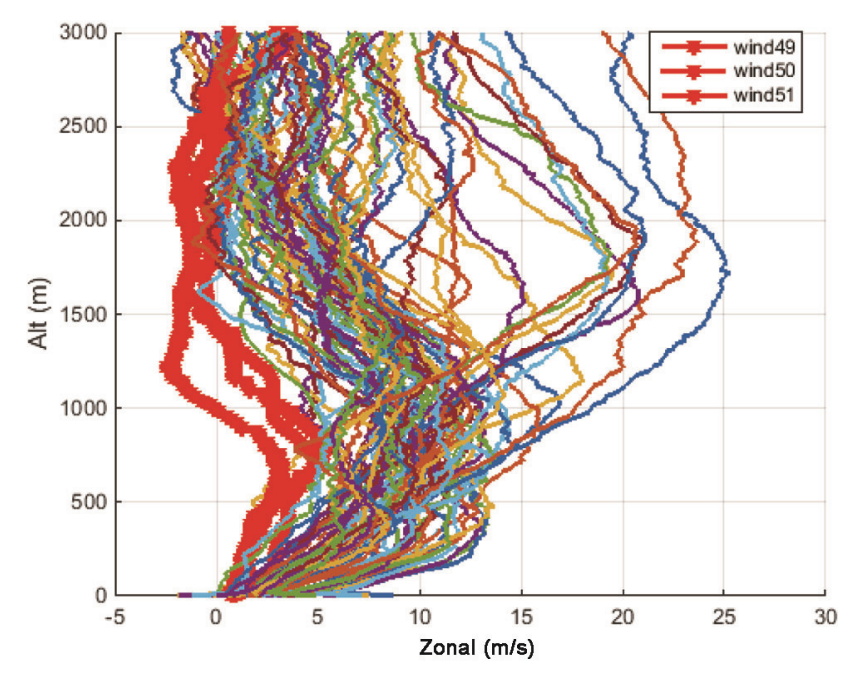

Figure 5. Zonal wind component of measured winds.

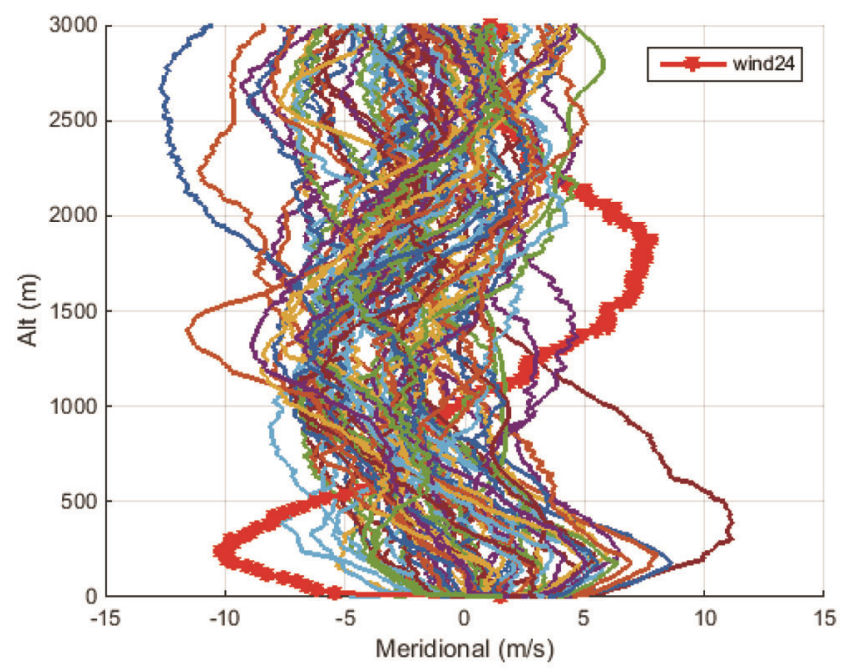

Figure 6. Meridional wind component of measured winds.

The impact ranges are minimum for a few wind number profiles as shown in Figure 5, due to near-zero magnitude of zonal component. Therefore, it is concluded that wind with positive zonal components of more than 3$4 \mathrm{~m} / \mathrm{s}$ is required to have impact range $>400 \mathrm{~m}$. Another typical profile as shown in Figure 6 has high shear in meridional components and this results in higher total AOA during parachute deployment. 
From these wind sensitivity studies, it is concluded that wind measurement monitoring is required one week prior to the launch date. Therefore winds were measured every day morning at 7 a.m. from 5 June to 4 July 2018, and used to evaluate the performance in terms of critical parameters on mission requirement, i.e. impact range and total AOA of separated CM during parachute deployment. Simulations were carried out for nominal and off nominal cases considering all the above measured winds. Figure 9 shows statistics of impact range during parachute deployment. The figure shows that in all cases the required minimum impact range for each measured wind case is met. Impact range more than $1 \mathrm{~km}$ is met for all winds, except for one case.

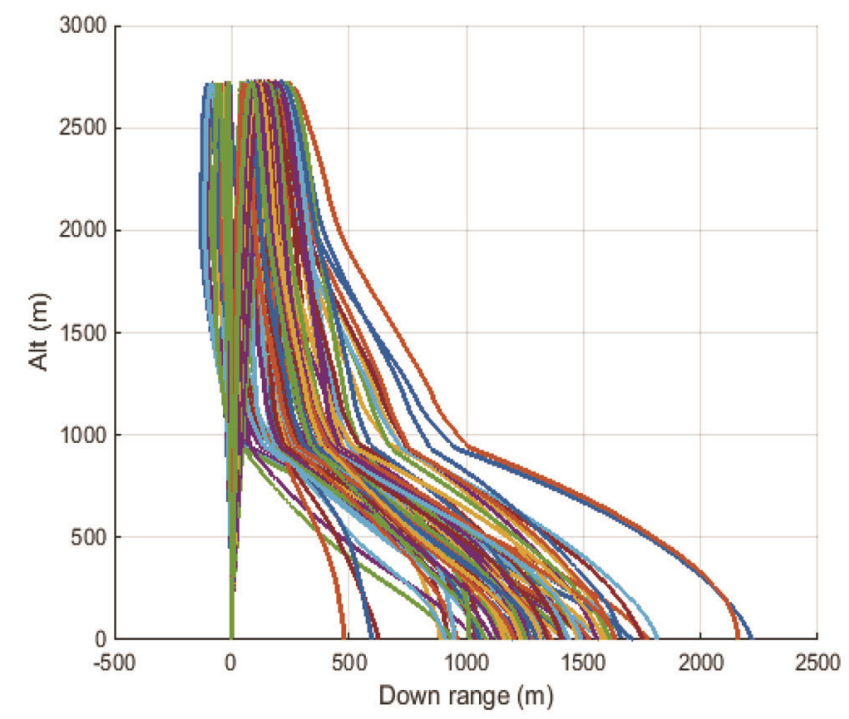

Figure 7. Down range profiles for CM.

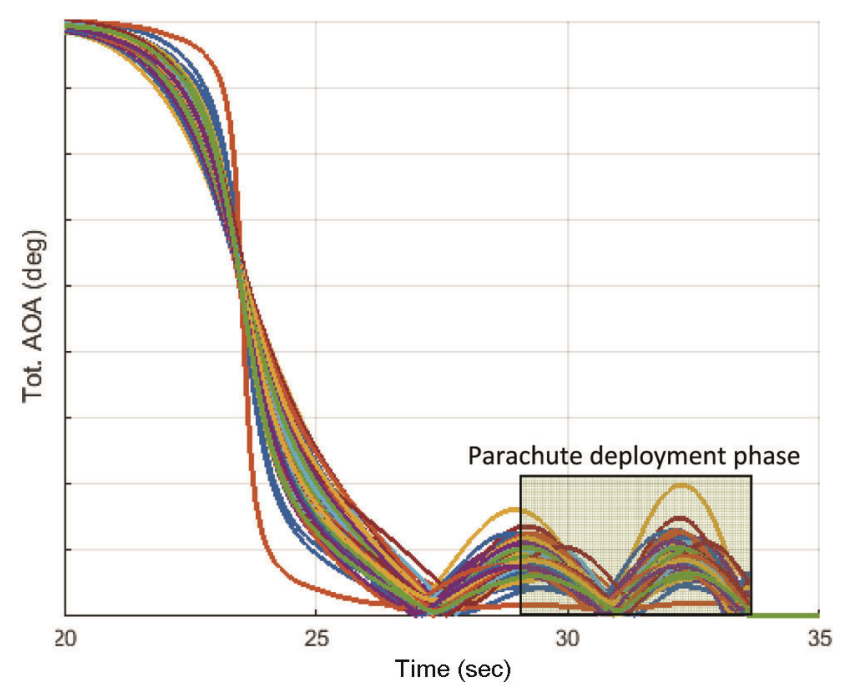

Figure 8. Total angle of attack of separated CM.

\section{Monte Carlo analysis}

Sensitivity of all measured quantities which are involved in the mathematical modelling of PAT mission simulation are understood by simulating certain deterministic cases using their $3 \sigma$ specifications. As PAT launch was scheduled in July, Monte Carlo (MC) simulations were carried out with nominal flight sequence and 473 July measured winds over SHAR. The LEM, HEM and PM performances were randomly perturbed between their lower and upper bound thrust time profiles. The following are the observations from $473 \mathrm{MC}$ simulations:

- Maximum altitude at parachute deployment is $2.78 \mathrm{~km}$.

- Maximum dynamic pressure at CES-CM separation is $0.74 \mathrm{kPa}$.

- Maximum AOA during parachute deployment is $55^{\circ}$.

- Minimum down range is $177 \mathrm{~m}$.
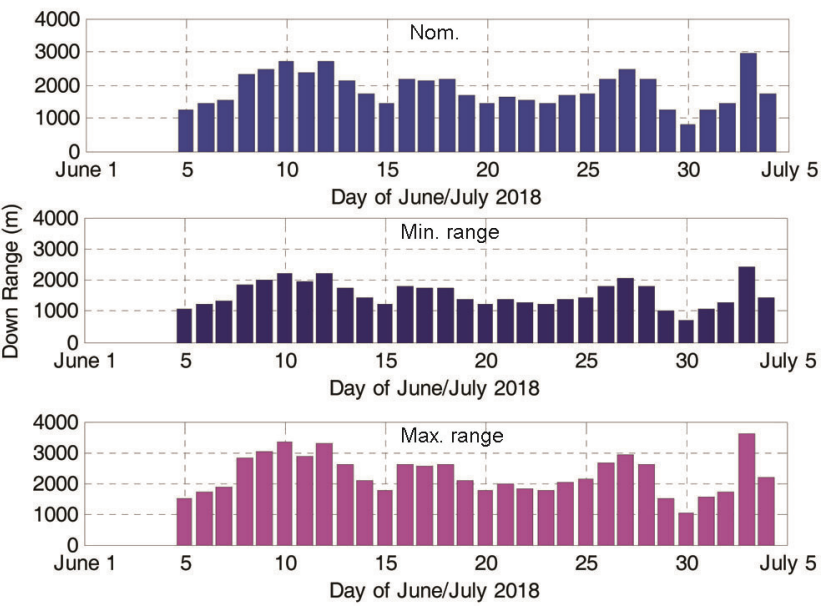

Figure 9. Impact down range for winds of 5 June to 4 July 2018 .

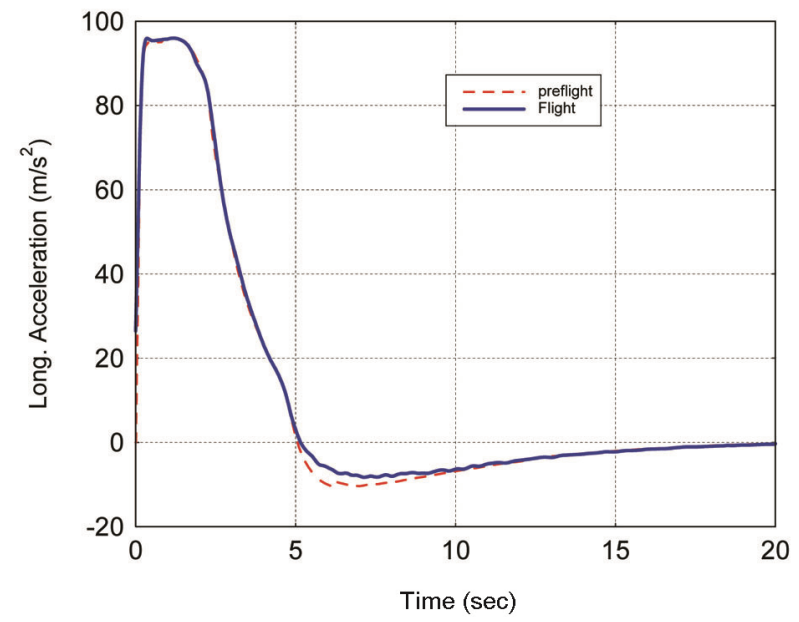

Figure 10. Longitudinal acceleration during CES phase: flight versus preflight. 
- About 2.1\% of MC cases violate both AOA and range constraints.

- All other mission constraints are met with good margin.

Four hundred MC simulations were carried out with each wind measurement over SHAR during launch campaign starting from T-6 day. Simulation winds were generated by incorporating temporal variations in the wind components. Critical trajectory parameters at various flight instances were monitored in MC simulations with all wind measurements. The pat launch campaign started from 29 June 2018. On launch day, MC simulations were carried out with the winds measured at $\mathrm{T}-4$ hour and $\mathrm{T}-1$ hour by incorporating temporal wind variation of $4 \mathrm{~h}$ and $1 \mathrm{~h}$ respectively. On all other days, MC simulations were done with wind measured at 7:00 IST by applying one-day temporal variations in zonal and meridional wind components.

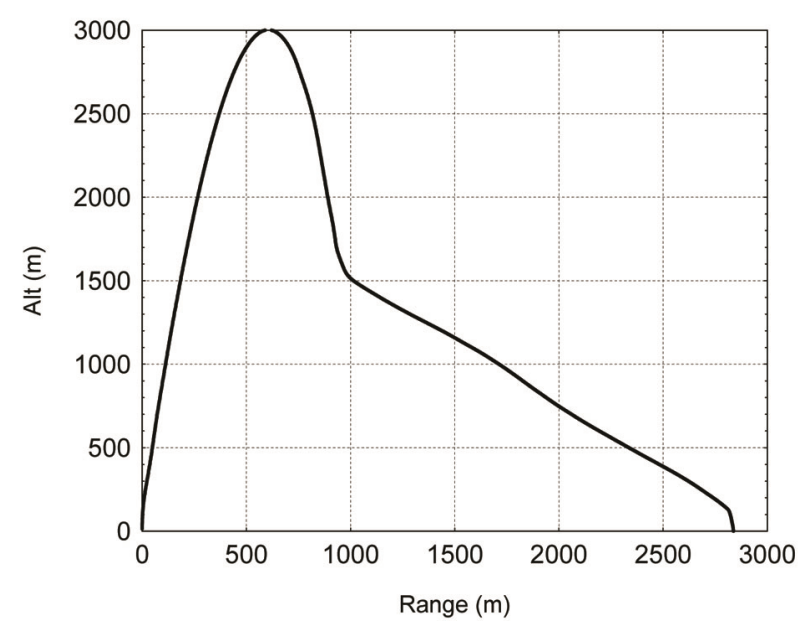

Figure 11. Altitude versus range profile: flight.

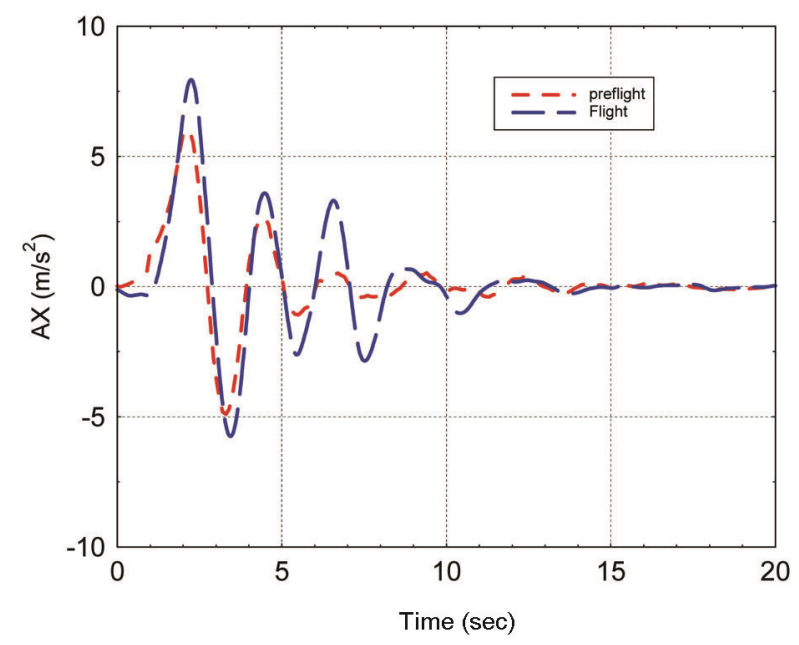

Figure 12. Lateral acceleration comparison: flight versus preflight.
The mission constraint with respect to AOA and range was met with wind measurements at $\mathrm{T}-1$ day, $\mathrm{T}-4 \mathrm{~h}$ and $\mathrm{T}-1 \mathrm{~h}$. With this confidence, the pre-fixed launch time was cleared based on MC simulations with respect to wind.

\section{Mission performance and deviations}

The post-flight analysis was carried out using flight measurements and the following conclusions are drawn.

The preflight prediction of dynamic pressure at CES and $\mathrm{CM}$ separation was $511 \mathrm{~Pa}$ and the flight observed value was about $993 \mathrm{~Pa}$. The dynamic pressure depends on the net axial acceleration during the Crew Escape system flight phase and the lateral acceleration during the pitch manoeuvre of CES phase and the total velocity achieved. The post-flight analysis indicates that the following parameters have changed from the preflight nominal values:

- LEM thrust misalignment: $0.3^{\circ}$ with azimuthally angle of $30^{\circ}$ from positive yaw axis.

- CES phase axial force coefficients: $0-5$ sec: $-4 \%$, 5-8 sec: $-10 \%, 8-20 \mathrm{sec}:-15 \%$.

- PM followed upper bound thrust profile.

The above effects increased longitudinal acceleration and lateral acceleration with respect to preflight. The reduction in longitudinal deceleration was observed during 5$8 \mathrm{sec}$ (Figure 10). Therefore, the vehicle achieved higher altitude than preflight prediction. The peak altitude during flight was about $3 \mathrm{~km}$ and the preflight prediction was about $2.7 \mathrm{~km}$ (Figure 11).

Also, the lateral acceleration was higher during flight (Figure 12) due to LEM thrust misalignment and PM upper bound performance. With higher lateral acceleration,

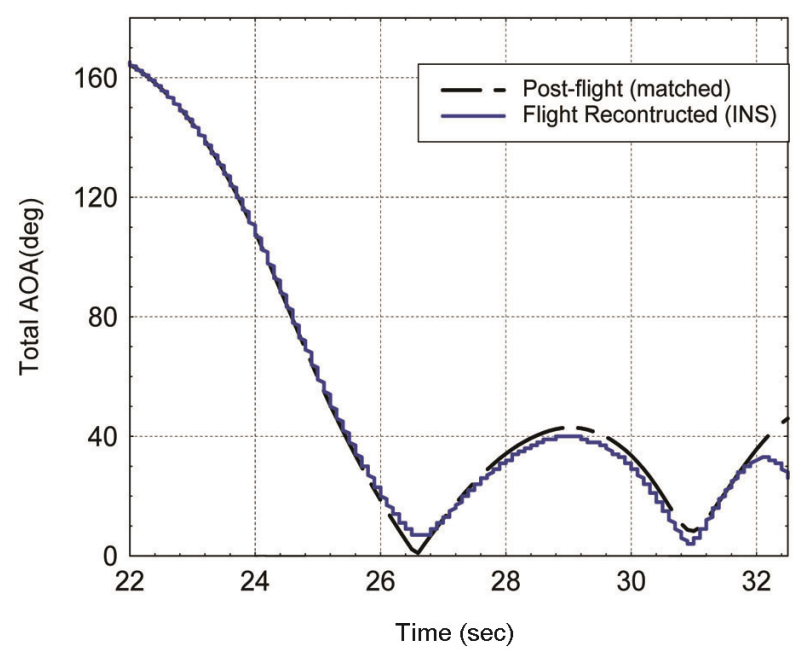

Figure 13. CM total angles of attack.

CURRENT SCIENCE, VOL. 120, NO. 1, 10 JANUARY 2021 
the vehicle has pitched down more, resulting in higher dynamic pressure at $\mathrm{CM}$ separation.

Figure 13 shows AOA comparison for flight data and the reconstructed AOA. The parachute operations are successful since the flight AOA is within $40^{\circ}$ during deployment phase, as further substantiated by video images.

\section{Conclusion}

- Trajectory simulations with six degrees of freedom were carried out using COMETS with preflight vehicle data. The time sequences of LEM and HEM ignition, PM ignition, CM/CES separation and parachute deployment were finalized based on preflight data and loaded in the on-board CES sequencer software.

- The flight parameters exhibited that mission specifications were successfully honoured, such as peak altitude of greater than $2.5 \mathrm{~km}$, down range greater than $400 \mathrm{~m}$ and dynamic pressure at CES/CM separation less than $3 \mathrm{kPa}$.

- CM reoriented successfully after separation from Crew Escape system was in passive sense to favoura- ble orientation angle of $\pm 40^{\circ}$ for successful parachute deployment.

- Flight trajectory parameters matched with perturbing preflight data. The perturbation levels are LEM thrust reduction to $1.5 \%$, thrust misalignment of $0.3^{\circ}$, CES axial force coefficients $\left(C_{\mathrm{A}}\right)$ reduction to $10 \%$, CES normal force coefficients $\left(C_{\mathrm{N}}\right)$ and CES side force coefficients $\left(C_{\mathrm{S}}\right)$ reduction to $3 \sigma$ and drag force coefficients $\left(C_{\mathrm{D}}\right)$ of drogue parachute increase to $15 \%$.

1. Hyle, C. T. et al., Abort Planning for Apollo mission. In AIAA 8th Aerospace Sciences Meeting, AIAA-70-0094, 1970.

2. Davidson, J. et al., Crew exploration vehicle ascent abort overview, AIAA-2007-6590. In AIAA Guidance, Navigation and Control Conference, August 2007.

3. Davidson, J. et al., Orion crew exploration vehicle launch abort system guidance and control analysis overview. In AIAA Guidance, Navigation and Control Conference, AIAA 2008-7148, August 2008.

4. Dhaoya, N. et al., Mission design and trajectory simulation for CES. In Symposium on Applied Aerodynamics and Design of Aerospace Vehicle (SAROD 2015), 3-5 December 2015, Trivandrum, India, Paper id CP 89.

doi: $10.18520 / \mathrm{cs} / \mathrm{v} 120 / \mathrm{i} 1 / 89-95$ 